\title{
Sociolinguística e Livro Didático: uma análise exploratória
}

SOCIOLINGUISTICS AND TEXTBOOK: AN EXPLORATORY ANALYSIS

\section{Abdelhak RAZKY * Sandra Regina FEITEIRO **}

Resumo: O presente estudo tem por objetivo analisar o tratamento da variação linguística nos livros didáticos de português do Ensino Médio e suscitar uma reflexão dos conceitos de 'certo' e 'errado', variação linguística, mudança linguística e preconceito linguístico. Nesse sentido, analisa se o livro didático discute a variação linguística, compreendendo-a como resultado de uma diversidade de fatores socioculturais de uma comunidade linguística. Nosso corpus é composto por uma coleção de Língua Portuguesa para o Ensino Médio, elaborada por Carlos Alberto Faraco, aprovada pelo Programa Nacional do Livro Didático (PNLD-2015). A pesquisa está inserida no diálogo entre a Sociolinguística e o ensino da língua materna, mais especificamente, nos estudos teórico-metodológicos de Bortoni-Ricardo (2004), Faraco (2004), Alkmim (2005) e Labov (2008), entre outros, além dos Parâmetros Curriculares Nacionais do Ensino Médio de Língua Portuguesa - PCNs (BRASIL, 2000). Para a obtenção de resultados, utilizamos a metodologia pautada na pesquisa descritivo-bibliográfica e documental com abordagem qualitativa. Conforme os resultados, verificamos que a elaboração atual, na referida coleção, destaca uma preocupação em incorporar os estudos linguísticos à heterogeneidade e diversidade linguística, fundamentados pela sociolinguística.

\footnotetext{
* Doutor em Linguística (1992) e Pós-Doutor (2003) pela Université de Toulouse Le Mirail. Professor associado nível 4 na Universidade Federal do Pará. Contato: razky@ufpa.br.

** Mestranda no Programa de Pós-Graduação em Linguística pela Universidade Federal do Pará (UFPA). Professora efetiva de Língua Portuguesa na rede pública do Estado do Pará (SEDUC-PA). Contato: sfeiteiro@gmail.com.
} 
Palavras-chave: Sociolinguística. Livro didático. Variação linguística.

Abstract: This study aims to examine the treatment of linguistic variation in Brazilian Portuguese textbooks for High School and prompts a debate about concepts like right and wrong, language variation, language change and language prejudice. In this sense, it considers whether the textbook discusses the linguistic variation, understanding it as a result of a variety of sociocultural factors of a linguistic community. Our corpus consists of a collection of Portuguese Language for High School, prepared by Carlos Alberto Faraco, approved by the National Textbook Program (PNLD 2015). The research is part of the dialogue between Sociolinguistics and mother tongue teaching, more specifically, in theoretical and methodological studies of Bortoni-Ricardo (2004), Faraco (2004), Alkmim (2005), Labov (2008), among others, in addition to the National Curriculum Parameters of High School Portuguese Language - PCN (BRASIL, 2000). The methodology is based on descriptive, bibliographical and documentary research and a qualitative approach. The results show, that the current development, in that collection highlights a concern to incorporate linguistic studies in the heterogeneity and linguistic diversity from sociolinguistic perspective.

Keywords: Sociolinguistics. Textbook. Linguistics variation.

\section{Introdução}

Ainda podemos observar, nas aulas de Língua Portuguesa (LP), o ensino da gramática normativa com base em prescrições de regras da variedade padrão descontextualizada do uso social, desvinculada de seu funcionamento. As atividades de produção textual, por exemplo, ainda se limitam ao uso de regras, priorizando a escrita em detrimento da oralidade e diversidade linguística. Vemos, portanto, que se trata de um conservadorismo que ignora as contribuições teóricas da Linguística Moderna, principalmente, dos estudos desenvolvidos a partir da segunda metade do século XX.

Reconhecer as conexões entre as análises dos processos de ensino de língua materna e a Linguística, nem sempre é fácil. Talvez, em razão da 
especialidade do pesquisador ou a maneira como o conhecimento científico é transmitido. Isso é diretamente influenciado no trabalho do professor que, muitas vezes, encontra-se indiferente às questões da área da linguagem e escolhe priorizar a prática em vez da teoria.

Diante dessas inquietações, surge a preocupação em analisarmos o ensino da língua portuguesa no livro didático em relação às contribuições sociolinguísticas. Para tanto, o objetivo deste estudo é analisar o tratamento da variação linguística nos livros didáticos de português do Ensino Médio e suscitar uma reflexão acerca de abordagens como noção de certo e errado, de variação linguística, mudança linguística e preconceito linguístico.

Para a realização deste estudo documental, escolhemos como objeto de análise a coleção Português: língua e cultura, organizada por Carlos Alberto Faraco, composta de três volumes, editada e publicada em 2013 e orientada para o Ensino Médio. O critério seguido para a escolha da coleção foi o de ter sido aprovada pelo Ministério da Educação (MEC) e, ainda, resenhada pelo Guia do Livro Didático (BRASIL, 2014). Dentre as dez coleções resenhadas, a coleção selecionada para este estudo recebe destaque pelo trabalho com a língua padrão numa perspectiva crítica embasada na Sociolinguística.

O Guia do Livro Didático (GLD) evidencia no quadro esquemático, item destaque, que a coleção traz "capítulos voltados para questões como variação e preconceito linguístico” (BRASIL, 2014, p. 53). Dessa maneira, motivamos também conhecer a concepção de funcionamento que essa coleção encaminha e que se encontra em evidência pelo Guia, pois entendemos que não pode haver demonstração de funcionamento autêntico da língua sem que a consideremos no contexto do comportamento social.

Destaca, ainda, a forma como são abordados os conhecimentos linguísticos que "se faz predominantemente dentro da perspectiva reflexiva e tem caráter funcional; secundariamente, há um direcionamento para a sistematização dos conhecimentos gramaticais" (BRASIL, 2014 p. 55). Com efeito, num instrumento como o livro didático, o trabalho que possui como objetivo a intenção de realizar uma reflexão sobre os fenômenos da língua, priorizando discussões sobre os aspectos sociais da língua, mostra-se como um fator bastante positivo para o ensino/aprendizagem da língua materna.

Nesse sentido, a coleção se mostrou ideal como fonte de análise que, ao expor uma abordagem sobre o funcionamento da língua em seu contexto 
social, conduziu-nos a estabelecer a hipótese de que a coleção analisada poderia apresentar um direcionamento adequado às variações linguísticas.

Para tanto, este estudo está organizado da seguinte forma: na primeira seção, apresentamos como está posto o ensino da Língua Portuguesa no que concerne à variação linguística. $\mathrm{Na}$ segunda seção, discorremos acerca das contribuições sociolinguísticas no livro didático de português. $\mathrm{Na}$ terceira seção, descrevemos a metodologia e análise da coleção. Encerramos o artigo com algumas considerações contemplando resultados do estudo.

\section{A Variação Linguística no Ensino de Língua Portuguesa}

O ensino da Língua Portuguesa e as discussões sociolinguísticas têm sido foco de estudos frequentes nos últimos anos. Por muito tempo, temos assistido à publicação de documentos explicitando diretrizes curriculares para nortear e embasar o trabalho pedagógico nas escolas brasileiras. Destacamos os Parâmetros Curriculares Nacionais do Ensino Médio (PCNs) como o documento que apresenta as competências referentes à disciplina de Língua Portuguesa. De acordo com esse documento, são explicitados "três conjuntos de competências: comunicar e representar, investigar e compreender, assim como contextualizar social ou historicamente os conhecimentos" (BRASIL, 2000, p. 15).

No bojo dessas competências, o professor lança mão dos conhecimentos linguísticos que o aluno já possui, e propõe investigações sobre aspectos específicos da língua a serem trabalhados, contribuindo, assim, para a ampliação dos conhecimentos que o aluno tem. Dessa forma, este poderá compreender a língua portuguesa, na norma culta, apresentando domínio de diferentes linguagens em diferentes condições de produção.

Nesse contexto interacionista, o livro didático exprime como um recurso que pode vir a ser um instrumento fundamental para uma proposta de ensino democrático da língua, desde que se apresente com abordagens sociolinguísticas visando à construção de uma cultura linguística liberta de preconceito social.

Essa preocupação alcançou grandes reformas políticas e, hoje, pelo menos teoricamente, notamos mudanças positivas. A concepção de língua dos PCNs/PNLD já nos atenta para a questão de que o ensino de Língua 
Portuguesa deve ser pluralizado, respeitando as diversidades linguísticas e o falante brasileiro, conforme declarado em Brasil (2000, p. 26):

A língua portuguesa, no Brasil, possui muitas variedades dialetais. Identificam-se geográfica e socialmente as pessoas pela forma como falam. Mas há muitos preconceitos decorrentes do valor social relativo que é atribuído aos diferentes modos de falar: é muito comum se considerarem as variedades lingüísticas de menor prestígio como inferiores ou erradas.

Diante do exposto, fica claro que a escola não pode ignorar as diferenças sociolinguísticas, uma vez que as variedades existentes são formas comunicativas que servem para contextos distintos na sociedade. Os professores, portanto, devem assumir uma concepção científica da língua, e não uma concepção que conduza ao entendimento de que a língua possua um fim em si mesma. Para tanto, surge a necessidade de investimentos em metodologias e/ou instrumentos de ensino elaborados a partir da preocupação com uma formação fundamentada nos aspectos sociais e no funcionamento da língua.

Por longo tempo no Brasil, entretanto, a variação linguística, como objeto de ensino, permaneceu distanciada da realidade pedagógica de muitos professores de língua materna (COELHO, 2007). Mesmo que, mais recentemente, identificarmos um grande número de pesquisadores e estudiosos desenvolvendo pesquisas na área da sociolinguística no Brasil - como Possenti, Tarallo, Bagno, Bortoni-Ricardo, dentre outros -, essa realidade ainda persiste. Esses estudos, todavia, estão sendo acrescentados, mesmo que lentamente, às aulas de língua portuguesa, pelo professor e pelo livro didático, essencialmente em relação às variações linguísticas.

A esse respeito, Coan e Freitag (2010, p. 1) reiteram afirmando que "apesar dos avanços significativos nas últimas décadas, as implicações decorrentes da correlação entre heterogeneidade linguística e ensino de Língua Portuguesa estão ainda longe de se esgotar.” Em Bortoni-Ricardo (2005), vemos que, com os estudos da Sociolinguística, acentuou-se a lacuna entre os componentes sociais e linguísticos da comunicação humana. Essa realidade ocorre, mas não em razão de ausência de pesquisas na área da Sociolinguística, 
pois são realizados anualmente diversos congressos nacionais e internacionais sobre linguística no Brasil - como, por exemplo, o Congresso Internacional de Dialetologia e Sociolinguística (CIDS), que já está se preparando para a IV edição e que recebe importantes estudiosos dessas áreas. Podemos acrescentar, ainda, os estudos de Pós-Graduação em nível de Mestrado e Doutorado de várias universidades que, por sua vez, possuem um banco de dissertações e teses com acesso livre pela internet, como também a existência de periódicos científicos que divulgam importantes pesquisas na área, contribuindo com novas abordagens para o ensino de língua portuguesa.

Nesse contexto, as orientações dos PCNs que buscam adequar o ensino da gramática normativa aos estudos linguísticos, junto com as pesquisas desenvolvidas em todo o território nacional voltadas para essa área, mostram um avanço significativo entre os estudos de prescrição e descrição linguística (BRASIL, 2000), como apresentaremos nesta análise.

Os documentos oficiais (PCNs) reforçam que a questão do preconceito linguístico é possível ser combatido no espaço escolar, pois este espaço educacional deve ter como um dos objetivos o respeito às diferenças. Assim, este estudo acredita no princípio de que a escola é responsável pela apropriação dos constructos teóricos relacionados à língua e sociedade, enfatizando a diversidade linguística em todas as suas modalidades.

Para tanto, faz-se necessário que a escola esteja ciente dessa prática articulada da sociolinguística e o ensino de língua materna, pois o que presenciamos, nos últimos anos, conforme Possenti (2005), é que, como não se costuma pensar sobre a língua, atribui-se o fracasso escolar ao fato de o aluno não saber escrever e nunca ao fato de o professor não saber ler variantes linguísticas e não reconhecer diferenças dialetais.

Esse desafio é ratificado em Alkmim (2002, p. 37), ao chamar a atenção para

O fato de que sociedades como a nossa tenham, em função de razões históricas e políticas, identificado a chamada língua padrão com os usos lingüísticos dos grupos urbanos socialmente superiores não pode justificar o exercício do preconceito e da discriminação lingüística.

Entendemos que não se trata, no entanto, de impor a diversidade linguística aos alunos, mas compreender que o falante traz consigo diferenças 
dialetais. De acordo com Calvet (2002, p. 12), "as línguas não existem sem as pessoas que as falam, e a história de uma língua é a história de seus falantes.”. Dessa forma, acreditamos que a escola tem o papel de garantir o direito do aluno de conhecer o funcionamento por meio das variações. Tarallo (2007, p. 8) define "variantes lingüísticas como sendo diversas maneiras de se dizer a mesma coisa em um mesmo contexto, e com o mesmo valor de verdade."

Bortoni-Ricardo (2005) corrobora essa ideia, destacando a indissociabilidade da variação à natureza da linguagem. A variação, para a autora, é o resultado da interação dos diferentes grupos no seio das normas linguísticas de uma comunidade. É um processo natural na língua e está fortemente condicionado socialmente. A língua só se dá conta desse processo porque é heterogênea e opera com regras variáveis. Por ser um fato natural e inevitável, portanto, essa heterogeneidade não pode e não deve ser ignorada, como acontece na maioria das vezes, pelo professor, pela escola e também pelo livro didático. Entretanto, não é o que ocorre com a coleção escolhida para este estudo. Já existe uma preocupação em mostrar que a variação linguística resulta dessa dinamicidade da língua, ela é viva e possível de transformações por diversas variáveis ou dimensões como a diatópica, diagenérica, diageracional, etc.

Diante disso, é necessário compreendermos que tanto a escola quanto os professores que atuam nela devem trabalhar a partir do pressuposto de que a língua é um fato social, um saber coletivo, que existe em função da interação do indivíduo com seus pares. Esse caminho pode ser trilhado por estudos sociolinguísticos, tendo como objeto de análise o livro didático, uma vez que, como dito anteriormente, é um instrumento muito presente no trabalho docente.

\section{Português: língua e cultura numa análise sociolinguística}

A coleção Português: língua e cultura propõe, a começar pelo título, uma abordagem que busca equilibrar o estudo do texto com reflexões intuitivas e sistemáticas sobre a língua, com o objetivo de oferecer aos estudantes uma compreensão da realidade estrutural e sociocultural da língua.

Tem três volumes, um para cada série do Ensino Médio. Os capítulos estão organizados em cinco blocos que apresentam, de forma articulada, 
diferentes gêneros textuais, tendo o texto como objeto linguístico central em todos os capítulos. A escolha desse objeto justifica-se pela crença de que é por meio do texto que as práticas sociointeracionais se concretizam, dando vida efetiva à linguagem.

À guisa de contribuição, o Guia de Livros Didáticos (BRASIL, 2014, p. 52) apresenta, ainda, uma valiosa descrição da coleção:

... organizada como um compêndio, a coleção apresenta uma proposta de ensino/aprendizagem que leva o aluno a refletir sobre os fatos de linguagem em contextos de uso. Nessa perspectiva, ganham relevo na coleção discussões a respeito do funcionamento da língua e da linguagem como linguagem verbal e não verbal, origem da linguagem, língua como um sistema complexo e flexível, variação linguística.

Diríamos, pois, que o trabalho da coleção centra-se claramente na reflexão das relações que se estabelecem entre os objetos de ensino/ aprendizagem e suas funções socioculturais, localizando-se no campo do sociointeracionismo, a partir de temáticas diversificadas de acordo com as orientações dos PCNs em explorar assuntos transversais, como preconceito, por exemplo.

Vale ressaltar que, mesmo apresentando aspectos positivos no que diz respeito ao tratamento das variações linguísticas, os três volumes, porém, não trazem propostas específicas para a oralidade. Os volumes 1 e $2^{1}$, voltados para a $1^{a}$ série e $2^{a}$ série do Ensino Médio, respectivamente, apresentam uma abordagem mais ampla de forma mais aprofundada sobre as variações linguísticas. Isso demonstra que o autor prioriza o conhecimento das variações linguísticas mais no início do Ensino Médio, o que é coerente, uma vez que a diversidade linguística é um fato concreto e por isso deve ser compreendido em todos os níveis de ensino, principalmente, da educação básica.

Faraco (2013, p. 266), usa um mesmo texto no manual do professor dos três volumes. Nele, afirma entender que, a partir de diversidade linguística

1 As referências da coleção, no texto, serão feitas a partir dos livros: volume 1 refere-se a Faraco, 2013a; volume 2, a Faraco, 2013b; volume 3, a Faraco, 2013c. 
... os padrões de língua constituem, muna sociedade moderna e democrática, caracterizada por complexidade e pluralidade em elevado grau, indispensáveis elementos de agregação social e cultural. Isso porque, embora emergindo continuamente da diversidade sociolinguística, eles transcendem os limites do regional e do específico, contribuindo para a construção de uma relativa unidade linguística.

Essa prática, que integra o uso efetivo da língua, está presente nos três volumes por meio de leitura e fichamento das principais ideias dos textos, chamando a atenção para o fato de que a língua padrão é uma realidade variável, não é uniforme, muda no tempo e o padrão falado é diferente do escrito. Em verdade, para a realização de um bom trabalho com a variedade linguística, o professor deverá investir em propostas que extrapolem o que a coleção oferece.

Por isso entendemos que as aulas de língua portuguesa no Ensino Médio, não importando a série, devem propiciar para todos, em relação a conteúdos e conhecimentos, uma aprendizagem adequada aos princípios sociolinguísticos, apesar de que essa realidade caminha a passos lentos, como afirma Bortoni-Ricardo (2005, p. 19):

No Brasil, ainda não se conferiu a devida atenção à influência da diversidade lingüística no processo educacional. A ciência lingüística vem, timidamente, apontando estratégias que visam aumentar a produtividade da educação e preservar os direitos do educando.

Com isso, inferimos o quanto se deve levar em consideração que é no contexto social que as falas fluem e, principalmente, onde as interações entre os indivíduos acontecem. Por isso a urgência em disseminar conhecimentos sociolinguísticos através do livro didático, que possui um papel relevante em sala de aula. Vale dizer, ainda, que linguagem, sociedade e cultura não devem ser desvinculadas, estão fortemente ligadas entre si. Como afirma Calvet (2007), a etiqueta linguística é exatamente o registro da diversidade da linguagem de uma comunidade linguística.

Com base nessa ideia, é importante destacar que, na coleção de Faraco (2013a, 2013b, 2013c), há uma preocupação com os princípios 
sociolinguísticos para o ensino de língua materna, mostrando a relação existente entre língua e sociedade por meio da variação linguística, conforme mostraremos nas análises a seguir.

\section{Descrição Metodológica e Análise da Coleção}

Como já dito, o corpus é composto por uma coleção de livros didáticos de português correspondentes às três séries do Ensino Médio, elaborada por Carlos Alberto Faraco (volume 1, para a 1 a série - 2013a; volume 2, $2^{\mathrm{a}}$ série - 2013b; volume 3, $3^{\mathrm{a}}$ série $-2013 \mathrm{c}$ ), intitulada Português lingua e cultura e aprovada pelo PNLD-2014.

Nesta pesquisa, enfocamos o livro do professor, em que procuramos observar também os diálogos, as orientações e as recomendações destinadas aos docentes em relação às variações linguísticas, na tentativa de alcançarmos os objetivos a que nos propusemos.

Selecionada a coleção, desenvolvemos um estudo descritivo, com abordagem qualitativa, a partir da análise do tratamento da heterogeneidade linguística, das noções de certo e errado e de preconceito linguístico. Para isso, iniciamos com uma leitura prévia dos três volumes que compõem a coleção Português: língua e cultura, seguida de uma leitura minuciosa para então fazermos os recortes necessários para as análises. Com base nessas análises, reconhecemos os capítulos referentes à exploração da temática em foco.

Os capítulos da coleção estão organizados em cinco blocos. No entanto, daremos destaque para o segundo bloco que foi selecionado para análise, denominado "Enciclopédia da linguagem”. Destina-se à análise da língua e da linguagem. Encontra-se organizado em cinco capítulos distribuídos nos volumes 1 e 2 . Esse bloco tem por objetivo "proporcionar uma reflexão sobre a linguagem, visando promover a compreensão desse fenômeno, a fim de sustentar uma atitude crítica dos alunos frente aos preconceitos linguísticos.” (BRASIL, 2015, p. 51).

Neste caso, analisamos recortes de trechos originais dos três volumes da coleção, retirados das páginas dos livros que foram colocados em destaque. Atentamos, então, para os capítulos dos livros relacionados à investigação da temática em estudo que pudessem ir ao encontro dos objetivos propostos para esta pesquisa. Porém, diante da delimitação que requer uma investigação 
científica, não foi possível - e nem é nossa aspiração - abordar todos os capítulos do livro relacionados às variações linguísticas.

Esta coleção merece atenção quanto aos conhecimentos linguísticos, uma vez que estes são abordados, na maioria das vezes, inseridos numa perspectiva que oportuniza aos alunos refletir sobre os usos linguísticos, em capítulos voltados para questões como variação linguística e preconceito linguístico. No manual do professor estão apresentadas, de forma consistente e norteadora, as bases teórico-metodológicas adotadas pela coleção, com reflexões e sugestões relevantes para a prática docente no trabalho com a língua. A seguir, será apresentada a análise de fragmentos de textos da coleção ora em estudo.

\subsection{Português: língua e cultura. Volume 1}

Ao examinarmos a proposta de trabalho no volume 1 da coleção, constatamos que quatro capítulos são todos destinados ao estudo da linguagem. Tem como objetivo principal apresentar os dados sobre esse fenômeno para que o aluno possa expandir suas próprias capacidades linguísticas. Esse convite é feito logo no primeiro capítulo, na página 166, denominado Enciclopédia da linguagem. Transmite, desde o início, uma preocupação com os conhecimentos prévios sobre a relação existente entre língua e identidade.

Após dois capítulos dedicados à leitura de diversos gêneros sobre a linguagem e a interação social, dedica o $3^{\circ}$ capítulo à Complexidade das línguas, conduzindo à reflexão sobre a diversidade linguística e o preconceito linguístico, como veremos nos trechos a seguir: 
Fragmento 1 - Texto sobre a complexidade das línguas

Contudo, essa familiaridade toda não impede que alguns, não tendo ideia clara de como as línguas são, fiquem repetindo afirmações errôneas sobre elas. Se essas afirmações fossem inofensivas, não precisaríamos discuti-las. Ocorre que, em geral, elas carregam complicados preconceitos linguísticos e culturais e terminam por prejudicar os outros.

Um exemplo: certa vez, nós estávamos explicando a um grupo de alunos que as línguas humanas - embora muito diferentes entre si (e esse é um dado óbvio, certo?) — são qualitativamente idênticas. Quer dizer, não há diferenças qualitativas (essenciais) entre as línguas, considerando o modo como estas se organizam e funcionam: não há línguas mais "simples" ou "menos desenvolvidas", não há línguas "melhores" do que outras, não há línguas "toscas" ou "imperfeitas".

Talvez, começar pela compreensão de que suas línguas são tão complexas quanto a nossa (isto é, saber que elas não se distinguem qualitativamente da nossa) seja um ponto de partida importante para redesenharmos representações negativas (preconceitos) que ainda existem entre nós em relação aos povos indígenas do Brasil. Superando esses preconceitos, estaremos nos pondo ao lado deles na defesa de seus direitos - a maioria já consolidada em nossa legislação, mas ainda não respeitada integralmente na prática.

Fonte: Volume 1, p. 185.

O trecho ilustrado acima diz que “não há línguas mais 'simples' ou 'menos desenvolvidas', não há línguas 'melhores' do que outras, não há línguas 'toscas' ou 'imperfeitas' além de chamar a atenção dos alunos e professores 'para redesenharmos representações negativas (preconceitos) que ainda existem entre nós em relação aos povos indígenas do Brasil." Evidenciando que, neste capítulo, a língua é concebida como um sistema heterogêneo que pode variar.

Esse viés sociolinguístico destacado nesse trecho por meio do argumento de que no Brasil se falam muitas línguas é importante; entretanto, mais relevante ainda é a referência feita à existência, não só da língua portuguesa e suas variedades, mas a informação de que no Brasil também se falam outras línguas, entre elas as faladas pelos povos indígenas. Isso é necessário, também, pelo fato de que, em uma sala de aula heterogênea como as do Brasil, o português pode não ser a única língua materna. Por fim, salientamos essa importância ainda, por ser o primeiro volume da coleção e já discutir claramente aspectos sociolinguísticos. 
Ainda nesse capítulo, o autor expõe o que vem a ser uma gramática orientando a reflexão para a ideia da sistematização e organização das línguas, mas no final da página 195, julga interessante fazer algumas "observações complementares" acerca dessa questão:

Fragmento 2 - Texto sobre o conceito de gramática

\begin{abstract}
Aprender a falar a lingua da comunidade tem, portanto, esta primeira grande dimensão: a criança constrói um saber (não consciente, como vimos acima)' com o qual ela será capaz de produzir e entender um número infinito de enunciados naquela língua. $\mathrm{O}$ domínio pleno dessa capacidade básica se dá por volta dos dois anos. Daí para frente, a criança apenas refinará seu saber, incorporando as sutilezas sociais que acompanham o uso da língua na comunidade.

Entre essas sutilezas estará a intrincada questão da chamada língua-padrão (ou norma-padrão). As gramáticas (no sentido de livros) que se vendem por aí não têm o objetivo de descrever a língua (como procuram fazer cientificamente os linguistas), mas tratam fundamentalmente das regras de "bom comportamento" linguístico, isto é, das regras que temos de seguir socialmente, em certas circunstâncias, se queremos que nosso modo de falar seja considerado "correto". Por isso é que chamamos essas gramáticas de normativas.
\end{abstract}

Fonte: Volume 1, p. 195.

$\mathrm{Na}$ verdade, é interessante observar a concepção de língua que é apresentada ao leitor quando enfatiza a diferença entre gramática e descrição linguística, permite refletirmos sobre a interação que se dá “... incorporando as sutilezas sociais que acompanham o uso da língua na sociedade”. O autor parte do princípio de que há uma relação dinâmica entre língua e sociedade com reflexos reais na educação, conforme afirma Tarallo (2007, p. 8): "não admite a existência de uma ciência da linguagem que não seja social.”

Considera, também, a orientação dos PCNs (BRASIL, 2000, p. 15) aos professores: "não se pode insistir na idéia de que o modelo de correção 
estabelecido pela gramática tradicional seja o nível padrão de língua ou que corresponda à variedade lingüística de prestígio."

Com base na análise desse trecho, o autor esclarece conceitos importantes ao dizer que a língua padrão é a mesma norma padrão com caráter único e coercitivo, normativo-institucionalizado quando se trata de um livro. Finaliza esse capítulo, destinado à compreensão da complexidade por que perpassa a língua, alertando para a existência das variedades linguísticas, do saber linguístico do falante, como vemos abaixo:

Fragmento 3 - Texto sobre a flexibilidade da língua

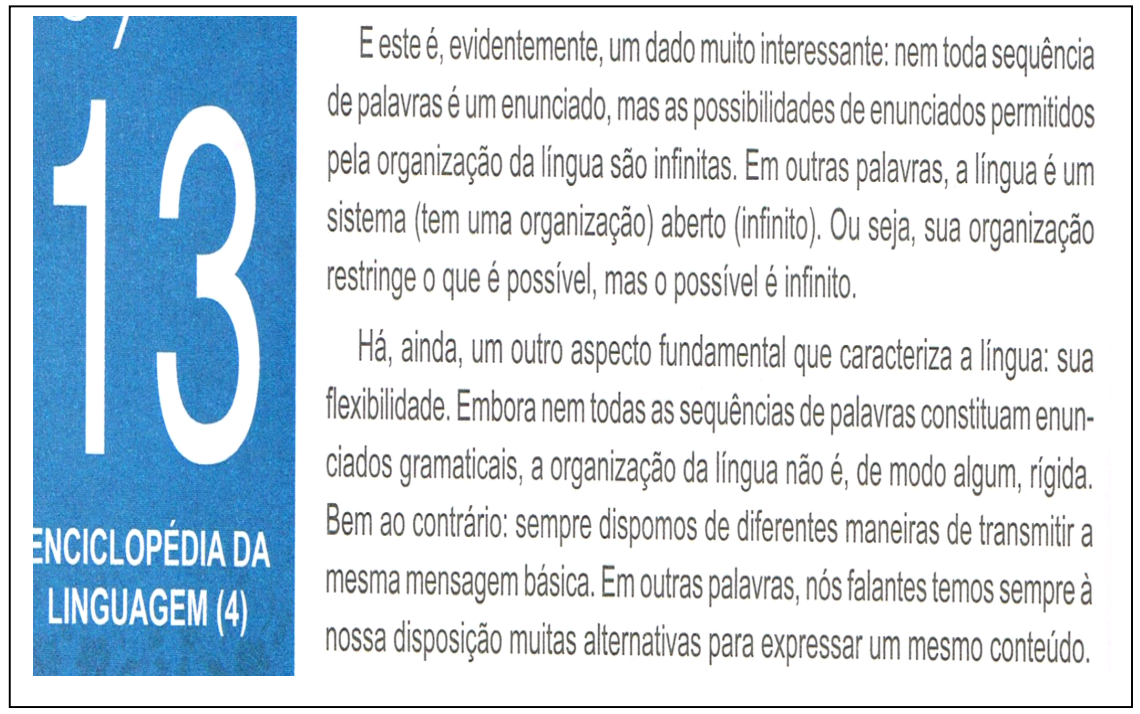

Fonte: Volume 1, p. 198.

Esse fragmento informa ao aluno a existência das variedades linguísticas contribuindo para o entendimento da flexibilidade da língua e, principalmente, mostrando que é permitido aos falantes, moldar estilisticamente e explorar as inúmeras alternativas expressivas e lexicais da língua.

Concordamos com Faraco (2004, p. 2) quando afirma que: 
... cabe ao ensino ampliar a mobilidade sociolingüística do falante (garantir-lhe um trânsito amplo e autônomo pela heterogeneidade lingüística em que vive) e não concentrar-se apenas no estudo de um objeto autônomo e despregado das práticas socioverbais (o estrutural em si).

Com efeito, verificamos, nesse volume, a presença de muitos textos para leitura e debate, porém pouquíssimas atividades. Isso possibilita ao aluno refletir sobre a língua e adequar o uso nas várias e inúmeras situações a que poderá estar submetido.

Não podemos deixar de evidenciar que não há, em todo o livro, um enfoque dado aos diferentes níveis de linguagem, com base em sua origem social, histórica, cultural e regional. As questões referentes ao tema dizem respeito à leitura e reflexão acerca da complexidade e flexibilidade da língua, principalmente da liberdade que o falante possui ao fazer uso dela. Demonstrando, portanto, um significativo avanço em relação ao tratamento da variação linguística nos livros didáticos de língua portuguesa.

Por fim, o volume apresenta algumas questões que têm como objetivo maior despertar no aluno o caráter de variedade de fala, ratificando Bortoni-Ricardo (2005) ao salientar a necessidade de acabarmos com o mito de que a língua padrão é a única forma correta de trabalhar o ensino/ aprendizagem da língua materna, mas que precisamos mostrar a dinamicidade a que está exposta.

\subsection{Português: língua e cultura. Volume 2}

Enquanto no volume 1 o bloco Enciclopédia da Linguagem aborda somente alguns pontos concernentes às características da língua, no volume 2, entretanto, o capítulo 10 - e único do referido bloco - traz como temática principal "A variação linguística" e chama atenção para o que vai ser trabalhado no decorrer do capítulo em relação à pluralidade linguística. Essa constatação acerca do caráter dinâmico da língua, apresentada em toda a coleção, principalmente neste volume, confirma a seriedade do autor em adotar as orientações dos Parâmetros Curriculares Nacionais para o Ensino Médio. Podemos verificar no fragmento abaixo: 
Fragmento 4 - Texto sobre variedades linguísticas

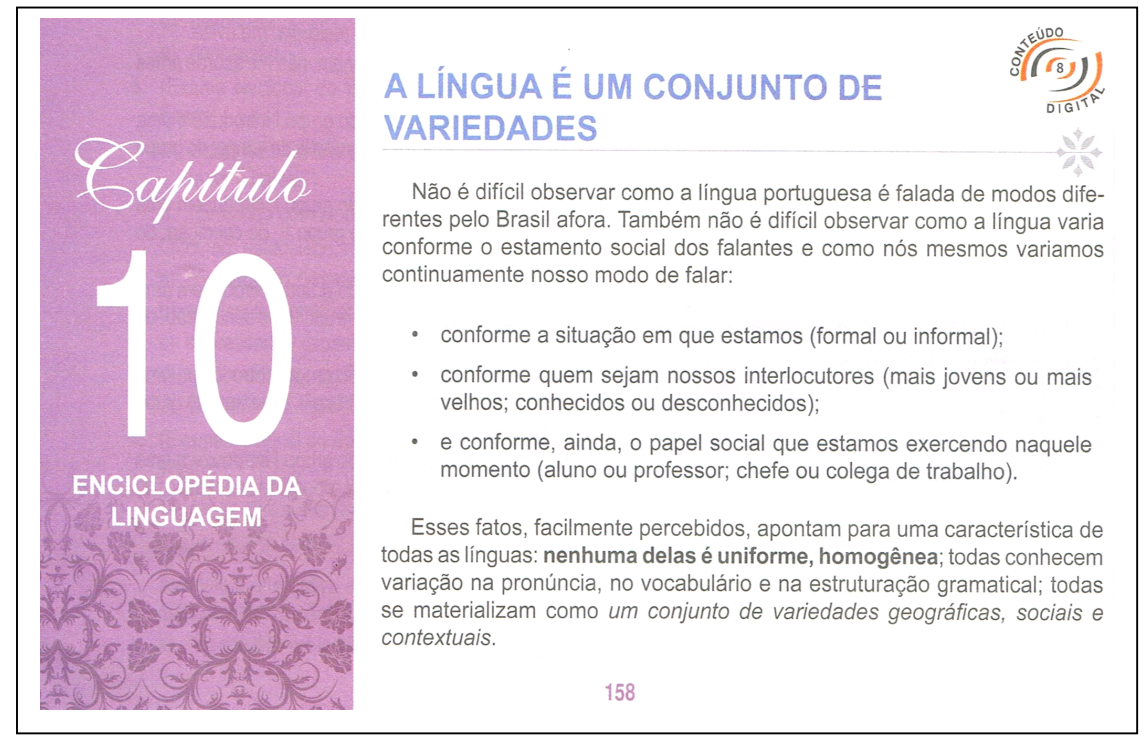

Fonte: Volume 2, p. 158.

Identificamos, nesse texto introdutório, uma preocupação do autor em apresentar diversos fatores das dimensões diageracional, diastrática e diatópica que influenciam a variação linguística. A existência dessas variáveis sociais destacadas corrobora a conscientização do aluno sobre a caracterização da heterogeneidade linguística do português brasileiro: "nenhuma delas [línguas] é uniforme, homogênea;...” (grifos do autor).

Percebemos, em todos os textos trabalhados neste capítulo 10, que o autor adota de forma adequada o tratamento dado, do ponto de vista teórico, à terminologia relacionada à variação linguística, uma vez que é comum a grande confusão feita por alguns autores no emprego de termos como "norma culta", "língua culta", "língua padrão", "variedade" "variante" etc.

Seguindo as leituras de diversos textos sobre variedades linguísticas, o autor menciona a pluralidade de línguas existentes no Brasil. E, para viabilizar essa proposta, neste capítulo, o autor apresenta textos que seguem um raciocínio que possibilita ao professor trabalhar sobre o preconceito linguístico. Apresentamos a seguir, um trecho dessa discussão: 
Fragmento 5 - Texto sobre a variação diatópica

\section{Um dado linguístico interessante a respeito do Brasil}

Em várias regiões do País, convivem, num mesmo espaço geográfico, diferentes variedades regionais. Esse fenômeno é decorrência dos movimentos migratórios de grandes contingentes populacionais que ocorreram durante o século 20: a migração de nơrdestinos para o Centro-Sul, a migração de sulistas para o Centro-Oeste e o Norte e o grande êxodo rural, que, em pouco mais de 50 anos, inverteu a distribuição da população entre cidade e campo, tornando o nosso país um dos mais urbanizados do mundo e trazendo para o espaço urbano os falares rurais brasileiros.

Precisamos, então, estar sempre alerta. A discriminação social pelo modo de a pessoa falar é tão condenável como qualquer outro gesto discriminatório. É fundamental ressaltar isso porque o preconceito linguístico (isto é, a discriminação motivada pelo fato de o outro falar diferente. está alastrado pelo nosso país, mas dele temos ainda pouca consciência, o que contribui para aumentar os seus efeitos nocivos.

Um caminho interessante a trilhar na luta contra o preconceito linguístico é acostumar os nossos ouvidos a captar essa grande variedade linguística regional brasileira e perceber o quanto de riqueza ela revela da nossa história e da nossa cultura.

Em termos simples: curta apaixonadamente a variação linguística! Desenvolver um olhar positivo para o outro, uma atitude receptiva da diferença, é parte indispensável do processo de vencer a discriminação e o preconceito.

Fonte: Volume 2, p. 160.

Em todos os textos deste capítulo, Faraco destaca que a língua é "um conjunto de variedades" e, com o auxílio de diferentes textos, explora a variação na dimensão geográfica, como podemos perceber nos trechos selecionados para análise. Colocar a discussão de variações linguísticas de cunho regional é de grande relevância no processo de educação linguística pelo qual deve passar todo usuário da língua; sobretudo, os que vivem em um país como o nosso, de tão grandes dimensões territoriais e de tão vasta diversidade linguística.

Constatamos, em uma das pouquíssimas atividades estruturadas, uma proposta que proporciona a percepção das questões sociais que envolvem a língua, ou seja, que trabalha os contrastes, os conflitos, aproximações e distanciamento entre as variedades estigmatizadas e as variedades de prestígio, 
contribuindo, portanto, para o combate ao preconceito linguístico, tão forte em nossa sociedade. Para essa abordagem, o autor utiliza como atividade a leitura e análise do tex to Não existem línguas uniformes, de Sírio Possenti, como vemos a seguir:

Fragmento 6 - Texto sobre a língua como uma realidade variável

4. Para concluir nossas discussões, leia o texto abaixo e localize os principais pontos que coincidem com o que dissemos na nossa apresentação da língua como uma realidade variável:

\section{Não existem línguas uniformes}

Sírio Possenti

Alguém que estivesse desanimado pelo fato de que parece que as coisas não dão certo no Brasil e que isso se deve ao "povinho" que habita esse país (conhecem a piada?) poderia talvez achar que tem um argumento definitivo, quando observa que "até mesmo para falar somos um povo desleixado". Esse modo de encarar os fatos de linguagem é

bastante comum, infelizmente. Faz parte da visão de mundo que as pessoas têm a respeito dos campos nos quais não são especialistas. Em outras palavras, é uma avaliação falsa. Mas, como existe, e como também é um fato social associado à linguagem, deve ser levado em conta.

E como produzir a uniformidade, se a variedade linguística é fruto da variedade social? Esta é uma questão sem dúvida interessante. Pesquisas feitas em vários países mostram que há uma diferença na fala de homens e de mulheres, por exemplo. A fala das mulheres é mais semelhante à norma culta do que à dos homens. Isso seria resultado de um comportamento linguístico mais "correto" por parte das mulheres, comportamento que resulta de valores que fazem com que esperemos comportamentos diferentes por parte de homens e mulheres, sendo que esperamos comportamentos mais corretos (o que quer que sejam) por parte das mulheres. Comportar-se como homem, em nossa sociedade, inclui ser menos correto do que uma mulher (menos gentil, menos educado, mais descuidado). O resultado de tais valores é que, para um homem, falar mais corretamente é mais ou menos como usar uma saia, segundo ilustrativa comparação do sociolinguista inglês Peter Trudgill.

O que fazer para uniformizar a linguagem de homens e mulheres? Não é necessário imaginar uma solução radical, como eliminar um dos sexos. Mas, poder-se-ia questionar seriamente os valores machistas que produzem esta diferença. Nesse sentido, uma discussão sobre valores sociais pode ser uma aula de português mais valiosa e frutífera do que uma aula com exercícios para eliminar gírias, regionalismos e solecismos.

POSSENTI, Sírio. Por que (não) ensinar gramática na escola. Campinas: Mercado Aberto, 1996. p. 33-37.

Fonte: Volume 2, p. 170. 
Nessa proposta de atividade, percebemos que o texto escolhido para leitura aborda de forma consistente fatores da dimensão externa da língua, ratificando a heterogeneidade da língua, tema discutido em todo o capítulo. O autor do texto destaca de forma reflexiva a variação diatópica, a diastrática e a diafásica, classificando-as como fatores que se encontram numa dimensão externa da variação, ou melhor, professor e aluno são convidados a debater sobre os fatores extralinguísticos, aqueles que se encontram fora da estrutura da língua.

Para a Sociolinguística, esses fatores são tão importantes quanto os linguísticos. Os fatores extralinguísticos foram foco do estudo pioneiro de Labov (2008), realizado na Ilha de Martha's Vineyard, Massachusetts, em 1962, sobre a variação dos ditongos /ay/ e /au/. A maior contribuição desse estudo foi mostrar a grande influência que os fatores condicionadores extralinguísticos podem ter sobre a língua, ou seja, as motivações sociais que a variação linguística pode apresentar.

Nessa perspectiva, ressaltamos um ponto bastante positivo neste volume, quando refere a presença do multilinguismo no Brasil. $\mathrm{O}$ autor procura revelar a existência de uma diversidade linguística muito acentuada no país, quando menciona os diversos estudos sobre língua padrão realizados, atualmente, em várias universidades. Incorpora, ainda, os ensinamentos da sociolinguística presentes na ficha de avaliação do PNLD (2015), que questiona se "o livro didático aborda os fatores socioculturais e políticos que entram em jogo no estabelecimento e difusão de ideais e padrões linguísticos e se considera a língua padrão no contexto da variação linguística, sem estigmatizar as demais variedades." Vejamos: 
Fragmento 7 - Texto sobre a língua padrão no Brasil

\section{Como sair dessa?}

A situação, como você pôde observar, não é das mais simples. Precisamos, porém, encontrar caminhos para enfrentá-la eficazmente. A língua-padrão é, como procuramos demonstrar anteriormente, uma questão relevante para a nossa sociedade como um todo. Mas ela só tomará um rumo positivo quando melhorarmos a definição de suas características (superando os equívocos da elite letrada do século 19) e reorganizarmos o seu ensino, garantindo a sua ampla difusão social.

Do ponto de vista geral, a sociedade brasileira - por meio de seus estudiosos da língua portuguesa - precisa definir com mais objetividade os elementos linguísticos efetivamente utilizados pelos profissionais contemporâneos da escrita em seus textos.

Esse processo se sustenta necessariamente num trabalho científico de descrição da língua-padrão. Não pode ser fruto de mero palpite ou preferências individuais. É importante que você saiba que parte significativa desse estudo vem sendo desenvolvida pelos linguistas das maiores universidades do País, embora seus resultados não tenham ainda tido a necessária divulgação social. Nossas considerações, aqui, se baseiam nesses estudos.

Fonte: Volume 2, p. 165.

Conforme Bortoni-Ricardo (2005), a sociedade valoriza o uso da chamada norma. Tanto o erudito quanto o trabalhador braçal, todos admiram o falar bem dos que se comunicam mediante a variedade de prestígio do Português, cujas normas estão presentes na gramática. É interessante constatarmos que, nas sociedades modernas, como afirma a autora, os valores culturais associados à norma linguística de prestígio - considerada correta, apropriada e bela - são ainda mais arraigadas e persistentes que outros de natureza ética, moral e estética.

Assim, o trecho do texto de Faraco mostra que é importante a escola, os professores e o livro didático reconhecerem a existência das variedades linguísticas no ensino da Língua Portuguesa e revelar ao aluno a necessidade desse reconhecimento, tendo em vista que um mesmo falante pode se apropriar de diferentes usos da língua, dependendo da situação, de quem é seu interlocutor e de suas intenções. 


\subsection{Português: língua e cultura. Volume 3}

No volume 3 da coleção analisada, não identificamos capítulos específicos relacionados ao tratamento da variação linguística. Dos 13 capítulos que compõem o livro, não há nenhum destinado ao bloco Enciclopédia da Linguagem.

Interessante observar, porém, neste volume, a presença de uma sistematização de tópicos da análise gramatical da língua, sem abusar na nomenclatura. São capítulos destinados ao estudo do léxico e das sentenças simples e complexas, inseridas no bloco Almanaque Gramatical. No bloco Guia Normativo - que, pela denominação, espera-se uma abordagem das normas gramaticais - está organizada em capítulos que trabalham com temas relacionados com as características da língua padrão do Brasil, porém numa perspectiva crítica "embasada na Sociolinguística, explicita normas básicas dessa língua relativas à concordância, à regência, etc.” (BRASIL, 2014, p. 51). Apresenta, ainda, coerência entre o tratamento da variação linguística exposta no capítulo destinado ao tema com as demais abordagens dadas em toda a coleção. Conferimos no fragmento a seguir:

Fragmento 8 - Texto sobre tópicos de língua padrão.

\section{A LINNGUA-PADRÃO É UM PEIXE ENSABOADO}

Quando discutimos os fenômenos linguísticos, todos concordam com a existência e com as vantagens socioculturais da língua-padrão. No entanto, pouca gente - se é que há alguém - será capaz de descrevê-la rigorosamente. Por isso é que dizemos que a língua-padrão é um peixe ensaboado. E tanto mais difícil será defini-la quanto mais transformações sociais, políticas, econômicas ocorram em curto espaço de tempo em uma dada sociedade, como é o caso do Brasil.

Os gramáticos excessivamente conservadores têm grandes dificuldades em reconhecer que a língua-padrão não é uniforme (como toda manifestação linguística, ela é variável), que ela muda no tempo, que o padrão falado é diferente do padrão escrito e assim por diante.

Desse modo, se há alguns pontos em que não existem dúvidas sobre o que constitui o padrão (por exemplo, boa parte dos fenômenos referentes à concordância verbal), na maioria dos casos há pouca certeza e bastante controvérsia.

Como sociedade, ainda não resolvemos bem esta questão. Por isso, você vai encontrar autores condenando categoricamente certas construções ao lado de outros que consideram estas mesmas construções como próprias do padrão. Isso, claro, complica nosso estudo da língua-padrão.

Fonte: Volume 3, p. 182. 
Esse trecho chama a atenção para o fato de a língua padrão ser uma realidade variável, não ser uniforme, mudar no tempo e o padrão falado ser diferente do escrito. Por outro lado, a obra aponta as vantagens socioculturais da língua padrão. Apresenta de forma adequada a variação nos fenômenos gramaticais que não acontece somente nas áreas rurais ou mais pobres de nosso país, mas também nas camadas mais letradas da sociedade, favorecendo, assim, o entendimento do aluno sobre a heterogeneidade do português brasileiro. Por fim, pode-se afirmar ainda que as propostas são diversificadas, contemplando os vários níveis de estudo da língua, mas com ênfases em questões morfossintáticas, textuais e discursivas.

\section{Considerações Finais}

A coleção analisada, embora ainda não apresente uma abordagem ideal de ensino de língua portuguesa, demonstra a preocupação do autor em integrar os estudos linguísticos à heterogeneidade e diversidade linguística fundamentados pela Sociolinguística. Conquanto, é importante acentuar que, na ausência de uma formação sólida acadêmico-científica e de um conhecimento apropriado da Sociolinguística por parte do docente de Língua Portuguesa, o livro didático sozinho, mesmo que seja bem elaborado, não atingirá um resultado em que o ensino/aprendizagem de língua materna esteja pautado no respeito à diversidade linguística e ao multiculturalismo dos falantes.

É necessário, sobretudo, ampliar o estudo da variação linguística na coleção analisada, com base em atividades que versem sobre a ordem sintática, morfológica, fonológica e lexical em textos escritos e orais com questões de identificação, análise e reelaboração de textos que oportunizem o ensino/ aprendizagem de fenômenos linguísticos e não fique somente na reflexão sobre o processo interativo da linguagem. E que, nesse sentido, possa apresentar direcionamentos que insiram, via de regra, o trabalho com a realidade da língua e sua veemência para o tratamento com a variedade linguística, com atividades significativas e enriquecedoras.

O professor é, certamente, uma peça fundamental nesse processo. Sua formação deve, sem dúvida, ser tratada com uma atenção especial, cujo conhecimento seja autônomo e emancipado ao ponto de perceber que a 
presença do livro didático seja desnecessária. Por seu papel relevante no contexto escolar e, principalmente, no estudo da língua, o livro didático, portanto, deve ser um instrumento que dissemine conhecimentos científicos acerca do dinamismo da língua.

\section{Referências}

ALKMIM, T. M. Língua e discriminação. Jornal do Grupo de Tortura Nunca Mais, Rio de Janeiro, a. 17, n. 43, p. 12-12, dez. 2002.

ALKMIM, T. M. Sociolingüística: parte 1. In: MUSSALIM, F.; BENTES, A. C. (Orgs.). Introdução à Lingüistica: domínios e fronteiras. São Paulo: Cortez, 2005. p. 21-47.

BORTONI-RICARDO, S. M. Educação em lingua materna: a sociolingüística na sala de aula. São Paulo: Parábola, 2004.

BORTONI-RICARDO, S. M. Nós cheguemu na escola, e agora?

Sociolingüística \& educação. 2. ed. São Paulo: Parábola, 2005.

BRASIL. Secretaria de Educação Básica. Parâmetros Curriculares Nacionais para o ensino médio: Parte II - linguagens, códigos e suas tecnologias. Brasília: $\mathrm{MEC} / \mathrm{SEB}, 2000$.

BRASIL. Guia do livro didático: PNLD 2015: Língua Portuguesa. Brasília: MEC/SEB/FNDE, 2014.

CALVET, L.-J. Sociolingüistica: uma introdução crítica. Tradução Marcos Marcionilo. São Paulo: Parábola, 2002.

CALVET, L.-J. Políticas lingüisticas. São Paulo: Cultrix, 2007.

COAN, M.; FREITAG, R. M. K. Sociolinguística variacionista: pressupostos teórico-metodológicos e propostas de ensino. Domínios de Lingu@gem, Revista Eletrônica de Linguística, Uberlândia, v. 4, n. 2, p. 1-22, jul./dez. 2010. Disponível em: <http://migre.me/qHOfJ>. Acesso em: 1 nov. 2014. 
COELHO, P. M. C. R. O tratamento da variação lingüistica nos livros didáticos de português. 2007. Dissertação (Mestrado em Linguística) - Universidade de Brasília, Brasília. Disponível em: <http://migre.me/qHOju>. Acesso em: 28 nov. 2014.

FARACO, C. A. Norma-padrão brasileira: desembaraçando alguns nós. In: BAGNO, M. (Org.). Lingüistica da norma. São Paulo: Loyola, 2004. p. 37-61.

FARACO, C. A. Português: língua e cultura: língua portuguesa. $1^{\circ}$ ano, volume 1: ensino médio, manual do professor, 3. ed. Curitiba: Base, $2013 \mathrm{a}$.

FARACO, C. A. Português: língua e cultura: língua portuguesa. $2^{\circ}$ ano, volume 2: ensino médio, manual do professor, 3. ed. Curitiba: Base, 2013b.

FARACO, C. A. Português: língua e cultura: língua portuguesa. $3^{\circ}$ ano, volume 3: ensino médio, manual do professor, 3. ed. Curitiba: Base, $2013 c$.

LABOV, W. Padrões sociolingüísticos. Tradução Marcos Bagno et al. São Paulo: Parábola, 2008.

POSSENTI, S. Por que (não) ensinar gramática na escola. Campinas: Mercado de Letras; São Paulo: Associação de Leitura do Brasil, 2005.

TARALLO, F. A pesquisa sociolingüistica. 8. ed. São Paulo: Ática, 2007. (Série Princípios).

Recebido em: 28/02/2015 Aceito: $01 / 05 / 2015$ 